\title{
Muscarinic Agonist APD515
}

National Cancer Institute

\section{Source}

National Cancer Institute. Muscarinic Agonist APD515. NCI Thesaurus. Code C96734.

A liquid, oromucosal formulation containing a muscarinic agonist with potential antixerostomia activity. Upon application to the inside lining of the mouth, muscarinic agonist APD515 may locally act on muscarinic receptors on the salivary glands and may stimulate the production of saliva thereby relieving dryness of the mouth. 